\title{
Impact of sugar replacers on cognitive performance and function in rats
}

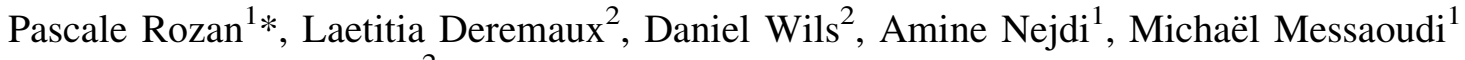 \\ and Marie-Hélène Saniez ${ }^{2}$ \\ ${ }^{1}$ ETAP - Ethologie Appliquée, Technopôle de Nancy-Brabois, 13 rue du Bois de la Champelle, Vandoeuvre-lès-Nancy F-54500, \\ France \\ ${ }^{2}$ ROQUETTE Frères, Lestrem F-62080, France
}

(Received 11 July 2007 - Revised 2 January 2008 - Accepted 19 February 2008 - First published online 1 April 2008)

Glycaemic responses to the dextrin NUTRIOSE ${ }^{\circledR} 6$ (Dex) and the MALTISORB ${ }^{\circledR}$ maltitol (Mal) have been studied previously but their effects on vigilance and cognitive performances are still not known. The present study assesses dose-related glycaemic responses following Dex administration and the hypothesis that Dex and Mal could modulate the glycaemic response, improve vigilance under stress conditions and improve cognitive performances in rats. The glycaemic responses following Dex and corn syrup GLUCIDEX ${ }^{\circledR}$ IT 21 (CoS) solutions at $0 \cdot 3,0 \cdot 5$ and $1.0 \mathrm{~g} / \mathrm{kg}$ body weight administered by oral administration (experiment 1) and glycaemic responses to three cereal bars (standard (CoS), Dex or Dex/Mal bar) (experiment 2) were evaluated. Rats having eaten cereal bars were submitted to vigilance and aversive light stimulus avoidance conditioning tests to assess their vigilance and cognitive performances. The first experiment showed that the glycaemic response to both products is dose-related and that $\mathrm{CoS}$ induced a glycaemic response three times higher than the Dex response. The second experiment showed the same glycaemic response for the three cereal bar-treated rats. Yet, an increase in the vigilance of Dex/Mal-treated rats as well as a better discrimination between two levers in the cognitive test for Dex- and Dex/Mal-treated rats were noticed. These results suggest that the glycaemic response is not the only factor to be considered in predicting the efficiency of a food ingredient on vigilance and cognitive performances: these behaviours are improved after Dex- and Mal-prepared cereal bar ingestion whereas the glycaemic response does not differ from the CoS-prepared bar.

Dextrin: Maltitol: Glycaemic kinetics: Cognitive performances: Rats

NUTRIOSE ${ }^{\circledR} 6$ (Dex) is a food dextrin composed of $\alpha-1,4$ and $\alpha-1,6$ linkages and non-digestible glucoside linkages ${ }^{(1)}$. These structural properties explain why this soluble fibre is incompletely hydrolysed and absorbed in the small intestine. About $15 \%$ is absorbed in the small intestine and about $75 \%$ is fermented in the large intestine. The fermentation process occurs along the whole digestive tract and there is no excessive fermentation in the large intestine. The remainder (about $10 \%$ ) is excreted in the faeces. Because Dex is fermented slowly, leading to progressive production of SCFA, energy is available for an extended period after a meal. The energy value of Dex is $7.1-8.4 \mathrm{~kJ} / \mathrm{g}(1.7-2.0 \mathrm{kcal} / \mathrm{g}$ ) (internal data $)^{(1)}$. Moreover, Dex exhibits a very low glycaemic index (GI) of 25 and a low insulinaemic index of $13^{(2)}$. Dex is mainly used for fibre enrichment in plenty of foodstuffs. MALTISORB ${ }^{\circledR}$ maltitol (Mal) is a cereal-derived sugar substitute of the polyol family. The metabolic fate of Mal is about $30-40 \%$ digestion in the small intestine and about $60-70 \%$ fermentation in the colon ${ }^{(3)}$. Its energy value is considered to be $10.0 \mathrm{~kJ} / \mathrm{g}(2.4 \mathrm{kcal} / \mathrm{g})$ and its sweetness is $0.8 \times$ the sweetness of sucrose (by weight). This sugar alcohol is classified in the very low GI category. The glycaemic response has been estimated to be 29 and the insulinaemic response to be 33 in healthy subjects ${ }^{(3)}$. Mal is mainly used in the production of sugar-free confectionery, chewing gum and chocolate.

Dex and Mal are interesting ingredients for the food industry to manufacture foods that do not induce a high postprandial increase in blood glucose. As they are sugar-free food ingredients, they can be used in replacement of sugar in sugar-free or reduced-in-sugar foodstuffs.

The addition of fibres as well as polyols or the substitution of sugar by fibres or polyols in the diet slows down the absorption of glucose ${ }^{(4)}$ and decreases the glycaemic response ${ }^{(3,5,6)}$. Because they combine slow glucose release in the small intestine with slow energy release in the colon through SCFA production, Mal and Dex deliver energy more progressively than starch or sugars, which are totally hydrolysed in the small intestine. Indeed, foods with a high GI produce a higher postprandial glycaemic peak and a greater overall blood glucose kinetic after consumption than do foods with a low $\mathrm{GI}^{(7)}$.

Moreover, the effect of the carbohydrates ingested could play an important part in the physiological and metabolic response. As glucose is the main metabolic fuel of the cells, the modulation of the amplitude of the postprandial hyperglycaemia could be of great importance in terms of physical and cognitive performances of individuals ${ }^{(8)}$. Concerning vigilance

Abbreviations: AUC, area under the curve; CoS, corn syrup GLUCIDEX ${ }^{\circledR}$ IT 21 ; Dex, dextrin NUTRIOSE ${ }^{\circledR}$ 6; GI, glycaemic index; Mal, maltitol MALTISORB ${ }^{\circledR}$.

* Corresponding author: Dr P. Rozan, fax +33 383446 441, email prozan@etap-lab.com 
performances, foods with specific glucose kinetics have to be recommended according to the type of exercise: foods with low glycaemic response before physical exercise and foods with high glycaemic response near the exercise ${ }^{(9)}$ to improve vigilance performances during the physical effort. As cognitive performances depend on the increased inflow of glucose into the brain cells, capacities for attention, memory and learning discrimination are optimised after the addition of low-GI foods to the diet ${ }^{(8,10)}$.

The objectives of the present study are to test the hypothesis that Dex and Mal could modulate the glycaemic response, improve vigilance under stress conditions and improve the cognitive performances in rats. The aim of the first experiment is to establish a dose-related glycaemic response following Dex administration. As carbohydrates in different food matrices can produce widely different blood glucose responses, the second experiment assesses the glycaemic response following consumption of cereal bars formulated with Dex, mixed or not with Mal. In this second experiment, the effect of Dex and Mal consumption on vigilance and cognitive performances are measured.

\section{Materials and methods}

\section{Animals}

Male Wistar/AF EOPS rats (Charles River Laboratories, SaintGermain sur l'Arbresle, France) were acclimatised for 1 week before the start of testing. At the start of experiments, rats weighing $310 \pm 10 \mathrm{~g}$ were divided into nine groups. They were housed in a well-controlled environment $\left(20 \pm 1{ }^{\circ} \mathrm{C}\right.$; humidity $50 \pm 5 \%$ ) with a reversed light cycle (lights from 21.00 to 09.00 hours). Feed (M 20; Dietex, Saint Gratien, France) and tap water were provided ad libitum. Rats used in the present study were treated according to rules published by the Association for the Study of Animal Behaviour Ethical Committee ${ }^{(11)}$ and the Canadian Council on Animal Care ${ }^{(12,13)}$. All standard operating procedures were in compliance with the European Community Council Directive 86/609/EEC of 24 November $1986^{(14)}$ on the approximation of laws, regulations, and administrative provisions of the Member States regarding the protection of animals used for scientific purposes.

\section{Products}

In experiment 1 , GLUCIDEX ${ }^{\circledR}$ IT 21 , a corn syrup $(\mathrm{CoS})$, and Dex were provided by ROQUETTE Frères (Lestrem, France). $\mathrm{CoS}$ was selected as the control, because it is wheat based, as is Dex. CoS is a spray-dried corn syrup obtained after hydrolysis of starch and purification. The dextrose equivalent is about $20-23$, its mean degree of polymerisation is 5 , and it contains $85.5 \%$ oligo- and polysaccharides, $6.65 \%$ maltose, $2.85 \%$ free glucose and $5 \%$ water. $\mathrm{CoS}$ is considered as a totally digestible starch derivative with $16.7 \mathrm{~kJ} / \mathrm{g}(4.0 \mathrm{kcal} / \mathrm{g})$ energy content and a GI near 100 (internal data).

Dex is a purified dextrin processed from starch heated at high temperature and adjusted to a low moisture level in the presence of an acid catalyst. The dextrin obtained is purified with activated carbon and demineralised by ion-exchange resins. Afterwards, the product is chromatographed and the high-molecular-weight fraction is spray-dried to process
Dex. The weight average molecular weight and the number average molecular weight are nearly 5000 and $2800 \mathrm{~g} / \mathrm{mol}$, respectively, and its mean degree of polymerisation is 17 . It contains $85 \%$ total dietary fibre with $76 \%$ of 1,4 linkages and $24 \%$ of 1,6 linkages, $2.3 \%$ reducing sugars and $3.5 \%$ water. The residual content of sugars is below $0.5 \%$ on a dry-weight basis, and thus the dextrin can be considered as sugar free. During the heating step, hydrolysis and repolymerisation occur. Repolymerisation creates new glycosidic bonds such as $(1,6),(1,2)$ and $(1,3)$ linkages in addition to the typical starch $\alpha(1,4)$ and $\alpha(1,6)$ linkages. This point confers to Dex a resistance against the action of endogenous glucidolytic enzymes and permits classification of the product among the soluble dietary fibres with a total fibre content of nearly $85 \%$.

In experiment 2, three tested cereal bars supplied by ROQUETTE Frères and produced by AAD (Artenay, France) according to an industrial process differed in CoS (standard bar), Dex and/or Mal (ROQUETTE Frères, France) contents. The three cereal bars consisted of cereal mix $(39 \%)$, fruits $(8 \%)$, sucrose $(3 \%)$, sorbitol $(3 \%)$, fat $(5 \%)$ and chocolate $(12 \%)$ as well as $\operatorname{CoS}(28 \%$ in the standard bar, $19 \%$ in the Dex bar and $12 \%$ in the Dex/Mal bar). The Dex and Dex/Mal bars contained $9 \%$ of Dex and the Dex/ Mal bar $7 \%$ of Mal. Their nutritional composition and energy value are given in Table 1 . Mal is presented as an anhydrous crystalline white powder containing $99.7 \%$ D-maltitol, $0.1 \%$ water and less than $0 \cdot 1 \%$ reducing sugars. It is a hydrogenated disaccharide, consisting of glucose and sorbitol, obtained by the hydrogenation of D-maltose. Its molecular weight, very close to that of sugar, is $344 \mathrm{~g} / \mathrm{mol}$.

\section{Experiment 1}

In order to determine the dose-related glycaemic responses following Dex administration compared with $\mathrm{CoS}$, seventytwo rats were randomly assigned into six groups of twelve rats. Dex or $\mathrm{CoS}$ were delivered by intra-gastric administration in $12 \mathrm{~h}$-fasted rats at the doses of $0.3,0.5$ and $1.0 \mathrm{~g} / \mathrm{kg}$ body weight $(\mathrm{BW})$. The glycaemic responses were assessed for $240 \mathrm{~min}$ and the glycaemic area under the curve (AUC) was calculated.

Blood glucose was determined using the reflectance photometry method (Glucotrend2; Roche Diagnostics, Maylan, France) according to the following design plan: two basal points at 30 and $5 \mathrm{~min}$ before administration of products (by oral administration in experiment 1 and by individual feeding in experiment 2), then every $15 \mathrm{~min}$ during the first $1 \mathrm{~h}$ after administration of products (at points $15,30,45$ and $60 \mathrm{~min}$ )

Table 1. Composition of the three cereal bars

\begin{tabular}{lrrr}
\hline & $\begin{array}{c}\text { Standard bar } \\
(\% \text { DS })\end{array}$ & $\begin{array}{r}\text { Dex bar } \\
(\% \text { DS })\end{array}$ & $\begin{array}{r}\text { Dex/Mal bar } \\
(\% \text { DS })\end{array}$ \\
\hline Protein & 5.12 & 5.15 & 5.21 \\
Fat & 11.15 & 11.17 & 11.20 \\
Carbohydrate & 68.15 & 69.49 & 70.41 \\
Including sugars & 34.76 & 29.64 & 25.02 \\
Fibre & 4.33 & 11.85 & 12.04 \\
Energy value (kJ) & 1387.31 & 1348.14 & 1313.01
\end{tabular}

DS, dry sample. 
and every $30 \mathrm{~min}$ during the last $3 \mathrm{~h}$ (at points $90,120,150$, 180,210 and $240 \mathrm{~min}$ ).

One drop of blood was sampled on the extremity of the tail and the glucose analysis was immediately carried out. The Glucotrend 2 was calibrated with a chip of calibration inserted in the apparatus before use and two control solutions of glucose (Accu-Chek Active Control; Roche Diagnostics) were tested.

\section{Experiment 2}

In order to determine the glycaemic response following consumption of $2 \mathrm{~g} / \mathrm{rat}$ of the three cereal bars formulated with different sweeteners as CoS (standard bar), Dex (Dex bar), Dex and Mal (Dex/Mal bars), forty-eight rats were randomly assigned into the three treatment groups, each with sixteen rats.

To avoid any effects due to neophobia during the testing day, small pieces of the tested cereal bars were given in the troughs of the home cages for $3 \mathrm{~d}$ to habituate the rats to eat their respective test products. During the next $4 \mathrm{~d}$ of the training period, the experimental bars were individually delivered on odd days (days 1, 3 and 5) from 09.00 to 09.15 hours, whereas standard laboratory chow was given on even days (days 2 and 4 ) at the same hour ${ }^{(8)}$. This first meal was followed by $4 \mathrm{~h}$ starvation until ad libitum feeding was allowed again for the remaining part of the dark phase. This forced fast corresponded to the period necessary to measure the glycaemia during testing on day 5. Rats that did not eat their entire portion were removed from the study.

In experiment 2, glycaemic kinetic measurements were performed as previously described in experiment 1 . The AUC of glycaemia obtained with the three cereal bars were calculated taking into account the mean between the two basal points.

To assess the cognitive performances of rats, a wash-out period was observed followed by two more experimental days (days 12 and 13). Rats received $2 \mathrm{~g}$ of cereal bars in the same conditions as described in the glycaemic kinetic test.

On day 12, $150 \mathrm{~min}$ after administration of the cereal bars, the rats were individually placed in a stressful swimming situation to test their cognitive ability to escape from this aversive situation and how much the improvement of their cognitive performance was resistant to an increased energy demand. For that, the rats were submitted to a physical workload in individual tanks $(30 \mathrm{~cm}$ diameter, $50 \mathrm{~cm}$ height) filled up with $30 \mathrm{~cm}$ of water at $25 \pm 1{ }^{\circ} \mathrm{C}$ containing in its centre a threaded metal rod ( $8 \mathrm{~mm}$ diameter, $20 \mathrm{~cm}$ height). To escape from this stressful environment, rats had $3 \mathrm{~min}$ to find the rod and to seize it and then to climb up to its top. The time taken to seize the threaded rod and to climb up to the top was recorded.

On day 13 , rats were subjected to a 5 min forced swim session, 20 min before placing them in the aversive light stimulus avoidance conditioning test to assess their cognitive performance $^{(15,16)}$ and $180 \mathrm{~min}$ after the administration of cereal bars. The preliminary forced swim step was done to physically exhaust the rats. Immediately after the exercise, rats were dried with a towel and then returned for $20 \mathrm{~min}$ to their home cages before the cognitive testing.

The aversive light stimulus avoidance conditioning test was performed by placing the animals in a strongly illuminated
(1200 lux) cage $(50 \times 40 \times 37 \mathrm{~cm})$ equipped with two levers. By pressing the active lever the rats switched off the light for $30 \mathrm{~s}$, whereas the inactive lever had no effect on the environment. The test lasted $20 \mathrm{~min}$. The total number of pressings on the two levers was recorded and the learning performance (for example, discrimination between the two levers) was determined by comparison of the numbers of active lever and inactive lever pressings recorded during the light period $^{(15)}$.

\section{Statistics}

An ANOVA or Kruskal-Wallis test was used to compare the various studied variables in the groups. When significant, a post hoc unpaired $t$ test (two-tailed) or Mann-Whitney test was performed. The results are expressed as mean values with their standard errors. For all the comparisons, differences were considered significant at $P<0 \cdot 05$. All statistical analyses were carried out using the StatView ${ }^{\circledR} 5$ statistical package (SAS Institute, Inc., Cary, NC, USA).

\section{Results}

\section{Experiment 1}

For the two tested products administered at three different dosages, the maximum of glycaemia was obtained $15 \mathrm{~min}$ after their administration (Fig. 1). A dose-related response was observed for each product and CoS provokes the highest response at the three doses compared with the glycaemic response of Dex-treated rats. The weakest response was observed with Dex at $0.3 \mathrm{~g} / \mathrm{kg} \mathrm{BW}$.

The ANOVA showed a significant difference between the glycaemic kinetics obtained 15, 30, 45 and 60 min after administration of the tested products (Fig. 1). The comparison of CoS with Dex showed significant differences all along the 15 $(t=7.73 ; P<0.001), 30(t=3.88 ; P<0.001), 45(t=3.94$; $P<0.001)$ and $60(t=3.68 ; P<0.005) \mathrm{min}$ at the same dose of $1.0 \mathrm{~g} / \mathrm{kg}$ BW. Significant differences appear at $15 \mathrm{~min}$ between the two products at the doses of $0.3 \quad(t=3 \cdot 82$;

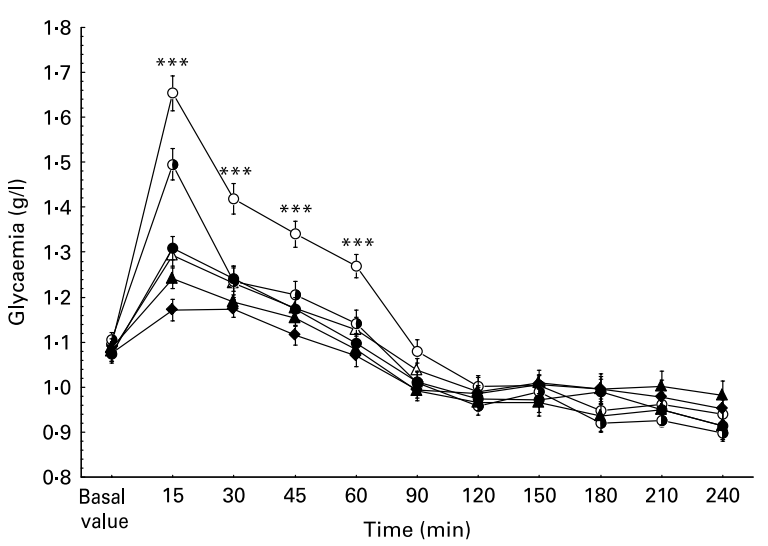

Fig. 1. Glycaemic postprandial responses following dextrin NUTRIOSE ${ }^{\circledR} 6$ (Dex) administration compared with corn syrup GLUCIDEX ${ }^{\circledR}$ IT 21 (CoS). (O), CoS at $1.0 \mathrm{~g} / \mathrm{kg}$ body weight (BW); $(\triangle)$, Dex at $1.0 \mathrm{~g} / \mathrm{kg} \mathrm{BW;} \mathrm{( \circlearrowleft ),} \mathrm{CoS} \mathrm{at}$ $0.5 \mathrm{~g} / \mathrm{kg} \mathrm{BW} ;(\boldsymbol{\Delta})$, Dex at $0.5 \mathrm{~g} / \mathrm{kg} \mathrm{BW;}(\bullet)$, CoS at $0.3 \mathrm{~g} / \mathrm{kg} \mathrm{BW;}(\bullet)$, Dex at $0.3 \mathrm{~g} / \mathrm{kg} \mathrm{BW}$. Values are means, with standard errors represented by vertical bars. ${ }^{* \star *} P<0.001$ (ANOVA). 
$P<0.001)$ and $0.5(t=6.11 ; P<0.001) \mathrm{g} / \mathrm{kg} \mathrm{BW.} \mathrm{A} \mathrm{trend}$ towards significance was observed between the tested products at the doses of $0.3 \mathrm{~g} / \mathrm{kg} \mathrm{BW}$ for the 30 and $45 \mathrm{~min}$ points $(t=1.80 ; P<0.10)$ and at $0.5 \mathrm{~g} / \mathrm{kg} \mathrm{BW}$ at $60 \mathrm{~min}(t=1.77$; $P<0 \cdot 10)$. However, no significant differences were observed between the two products at the doses of $0.3 \mathrm{~g}$ CoS compared with $0 \cdot 5 \mathrm{~g} \mathrm{Dex} / \mathrm{kg} \mathrm{BW}$ at 30,45 and $60 \mathrm{~min}$ (data not shown). The glycaemic response of rats of the Dex group, at the dose of $1 \mathrm{~g} / \mathrm{kg}$, is similar to that of rats of the CoS group at the dose of $0.3 \mathrm{~g} / \mathrm{kg}$ (Fig. 1): no significant differences were observed between these products at each time of measure.

Dose-related response was confirmed by the glycaemic AUC (Fig. 2). The ANOVA showed a significant difference between the glycaemic AUC obtained with the two tested products at the three doses $\left(F_{(5,66)}=25.5 ; P<0 \cdot 001\right)$. The comparison of CoS with Dex showed significant differences at the same doses of 1.0 and $0.5 \mathrm{~g} / \mathrm{kg} \mathrm{BW}$ and a trend towards significance was observed for the two products at $0.3 \mathrm{~g} / \mathrm{kg}$ (Fig. 2). The glycaemic AUC of rats of the Dex group, at the dose of $1 \mathrm{~g} / \mathrm{kg}$, is similar to that of rats of the CoS group at the dose of $0 \cdot 3 \mathrm{~g} / \mathrm{kg}$ (Fig. 2).

\section{Experiment 2}

For the three cereal bars tested, two peaks of glycaemia were observed: the highest peak was obtained $15 \mathrm{~min}$ after the administration of the bars and a second one appeared at $45 \mathrm{~min}$ for Dex and Dex/Mal bars and at $60 \mathrm{~min}$ for the standard bar after their administration. Twelve rats of the standard group, fifteen rats of the Dex group and thirteen rats of the Dex/Mal group had eaten their entire portion of cereal bars and were included in the statistical analysis. The ANOVA did not show significant differences between the glycaemic kinetics of the three cereal bars and between the AUC of the glycaemic kinetics of the three bars (Fig. 3).

In the stressful swimming situation, the Kruskal-Wallis test showed a significant difference between latencies to seize the rod of the three groups of rats (Table 2). As shown in Table 2,

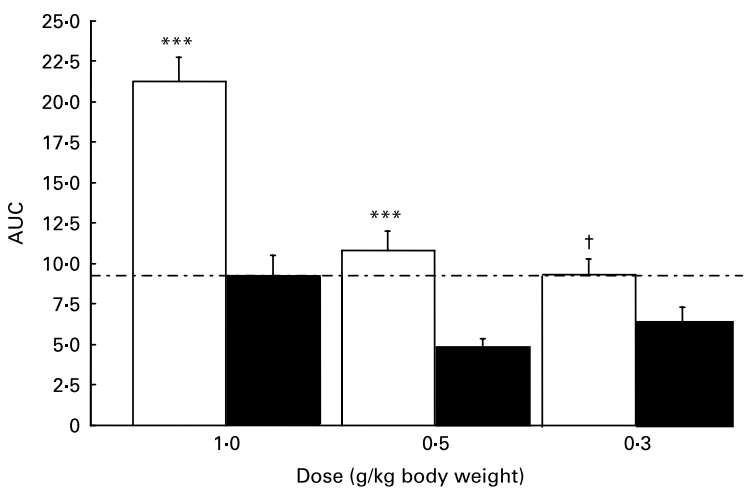

Fig. 2. Mean glycaemic area under the curve (AUC) after either corn syrup GLUCIDEX ${ }^{\circledR}$ IT 21 (CoS; $\square$ ) or dextrin NUTRIOSE ${ }^{\circledR} 6$ (Dex; $\square$ ) administration. Values are means, with standard errors represented by vertical bars. The AUC of Dex at $0.3 \mathrm{~g} / \mathrm{kg}$ and the AUC of CoS at $1.0 \mathrm{~g} / \mathrm{kg}$ are similar (-...-). ${ }^{* \star *}$ Mean value was significantly different from that of the Dexfed group $(P<0.001$; unpaired $t$ test). † Mean value was non-significantly different from that of the Dex-fed group $(P<0.10$ (trend); unpaired $t$ test). There was a significant difference between the glycaemic AUC obtained with the two tested products at the three doses $\left(F_{(5,66)}=25.5 ; P<0.001\right.$; ANOVA).

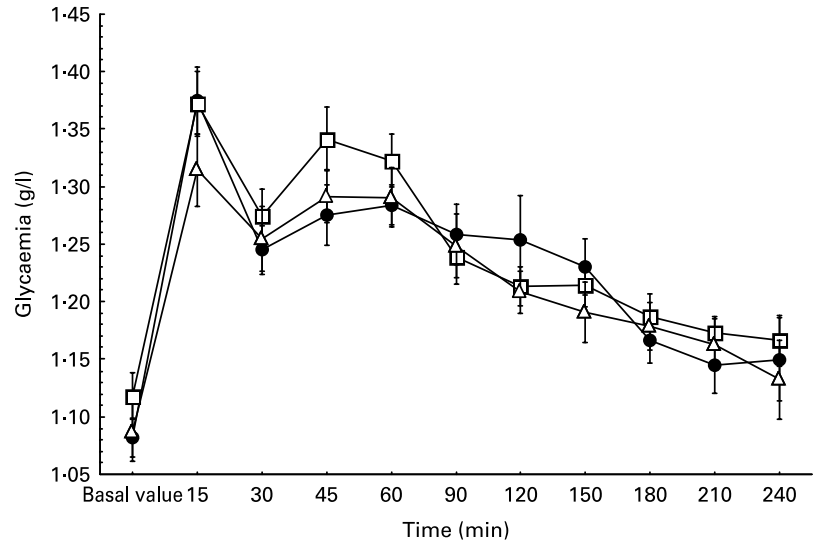

Fig. 3. Glycaemic postprandial responses following ingestion of three cereal bars: $(\bullet)$, standard bar containing corn syrup GLUCIDEX ${ }^{\circledR} I T$ 21; $(\square)$, bar containing dextrin NUTRIOSE ${ }^{\circledR} 6 ;(\triangle)$, bar containing dextrin NUTRIOSE ${ }^{\circledR} 6$ and maltitol MALTISORB ${ }^{\circledR}$. Values are means, with standard errors represented by vertical bars.

the rats of the Dex/Mal-bar group gripped the rod and climbed on to the top faster than those of the standard- and Dex-bar groups (latency to grip the rod: $\mathrm{U}=11.0 \quad(P<0.001)$; $\mathrm{U}=35.5(P<0.05)$, respectively, and latency to climb up to the top of the rod: $\mathrm{U}=16.5(P<0.05) ; \mathrm{U}=40.5(P<0.05)$, respectively).

Regarding cognitive performance (Table 3), there is a trend towards significance between the total number of pressings (active lever + inactive lever) for the 20 min testing period between the rats of the three groups.

The Wilcoxon $t$ test showed that the rats of the Dex/Malbar group discriminated significantly the active lever from the inactive lever from the first $5 \mathrm{~min}$ to the end of the aversive light stimulus avoidance conditioning test $(P<0.01$ at 5 , 10, 15 and $20 \mathrm{~min}$ ): they pressed the active lever twice more than the inactive lever. The rats of the Dex-bar group discriminated significantly the two levers after $15 \mathrm{~min}$ of test $(P<0.05)$ whereas the rats of the standard-bar group did not discriminate the two levers during the whole test (Fig. 4). The rats that did not eat the entire portion or did not press the two levers at least once were discarded from the statistical analysis: nine rats were included in the statistical analyses for the standard bar, fourteen rats for the Dex bar and eleven rats for the Dex/Mal bar.

Table 2. Vigilance and cognition following ingestion of three cereal bars*

(Mean values with their standard errors)

\begin{tabular}{|c|c|c|c|c|}
\hline \multirow[b]{2}{*}{ Groups } & \multicolumn{2}{|c|}{$\begin{array}{l}\text { Latency to grip } \\
\text { the rod (s) }\end{array}$} & \multicolumn{2}{|c|}{$\begin{array}{l}\text { Latency to climb up to } \\
\text { the top of the rod (s) }\end{array}$} \\
\hline & Mean & SEM & Mean & SEM \\
\hline Standard bar $(n 9) \dagger$ & $63 \cdot 0$ & $8 \cdot 9$ & $85 \cdot 8$ & $15 \cdot 3$ \\
\hline Dex bar $(n 15) \dagger$ & $48 \cdot 9$ & $7 \cdot 2$ & $85 \cdot 3$ & $15 \cdot 6$ \\
\hline Dex/Mal bar $(n 11) \dagger$ & $23 \cdot 3$ & $4 \cdot 2$ & $44 \cdot 0$ & $14 \cdot 3$ \\
\hline Kruskal-Wallis test & $\begin{array}{l}\mathrm{H}(2 \mathrm{df})=10.46 \\
P<0.01\end{array}$ & & $\begin{array}{l}\mathrm{H}(2 \mathrm{df})=7.43 \\
P<0.05\end{array}$ & \\
\hline
\end{tabular}

${ }^{*}$ For details of the cereal bars and procedures, see Table 1 and Materials and methods.

†The rat that did not eat its entire portion was discarded from the statistical analysis. 
Table 3. Total number of lever pressings*

(Mean values with their standard errors)

\begin{tabular}{|c|c|c|c|c|c|c|}
\hline \multirow[b]{2}{*}{ Groups } & \multicolumn{2}{|c|}{$\begin{array}{l}\text { Standard } \\
\operatorname{bar}(n \text { 13)† }\end{array}$} & \multicolumn{2}{|c|}{$\begin{array}{c}\text { Dex } \\
\operatorname{bar}(n 16)\end{array}$} & \multicolumn{2}{|c|}{$\begin{array}{c}\text { Dex/Mal } \\
\operatorname{bar}(n 15) \dagger\end{array}$} \\
\hline & Mean & SEM & Mean & SEM & Mean & SEM \\
\hline $\begin{array}{l}\text { Total lever } \\
\text { pressings }\end{array}$ & $17 \cdot 6$ & 5.8 & $28 \cdot 6$ & $5 \cdot 9$ & 38.3 & 8.5 \\
\hline $\begin{array}{l}\text { Kruskal-Wallis } \\
\text { test }\end{array}$ & $\begin{array}{l}H(2 \mathrm{df})=5.21 \\
P<0.10\end{array}$ & & & & & \\
\hline
\end{tabular}

${ }^{*}$ For details of the cereal bars and procedures, see Table 1 and Materials and methods.

$\dagger$ The rat that did not eat its entire portion was discarded from the statistical analysis.

$\ddagger$ Active lever + inactive lever.

\section{Discussion}

Dex and Mal are known for their sugar-replacement properties. They are low-digestible carbohydrates inducing very low glycaemic and insulinaemic responses and very little energy ${ }^{(1,3)}$. In the present study, a dose-related response is obtained between the postprandial glycaemia and the amount of $\mathrm{CoS}$ and Dex administered to rats. At each dose, the glycaemic kinetics and AUC of Dex are lower than the corresponding dose of CoS. At the dose of $1 \mathrm{~g} / \mathrm{kg} \mathrm{BW}$, the glycaemic kinetic of Dex is three times lower that the glycaemic kinetic of $\mathrm{CoS}$ and the AUC of Dex is about twice lower than the AUC of CoS. The shape of the curve with $1 \mathrm{~g} \mathrm{CoS} / \mathrm{kg} \mathrm{BW}$, that is to say a standard maltodextrin, is in agreement with a glucose response obtained in similar conditions ( LDeremaux and D Wils, unpublished results). The maltodextrin might be digested and absorbed as quickly as glucose alone, confirming the observation of Macdonald \& William $^{(17)}$. CoS can be replaced by Dex to reduce the postprandial glycaemic kinetics of rats. By extrapolation of these results, Dex could be useful to substitute sugars in beverages, which are simple food matrices.

For the three individual feedings, 56 to $81 \%$ of the rats of the standard group, 69 to $94 \%$ of the rats of the Dex/Mal group and 94 to $100 \%$ of the rats of the Dex group ate the entire portions of cereal bars. This indicated that the presence of dextrin and polyol in the cereal bars did not alter the taste of these bars and seemed to improve it comparing with the interest of rats for the standard bar.

Whatever the composition in carbohydrates of the cereal bars, the glycaemic response of rats after ingestion of $2 \mathrm{~g}$ of one of the Dex (180 mg Dex and $380 \mathrm{mg}$ CoS per rat) or Dex/Mal bars (180 mg Dex, $140 \mathrm{mg}$ Mal and $240 \mathrm{mg}$ CoS per rat) was similar to the glycaemic response of rats after ingestion of the standard bar $(560 \mathrm{mg} \mathrm{CoS}$ per rat), whereas the Dex and Dex/Mal bars were formulated with 9 and $16 \%$ low-digestible carbohydrates, respectively. The moderated glycaemic responses and the non-significant results observed after administration of the three cereal bars can be considered as expected because these kinds of foodstuffs are very rich in carbohydrates: the shape of the curve demonstrates a low, and spread out over time, glycaemic response. This composition could explain the second peak obtained at 45-60 min after ingestion whereas the first peak was due to fastest digestible carbohydrates.
Moreover, these conclusions can be linked with ingestion of the Dex and Dex/Mal cereal bars, because their glycaemia increased rapidly but did not reach the maximum value obtained with administration of pure standard maltodextrin in the first experiment $(1.37 \mathrm{~g} / \mathrm{l}$ for cereal bar $v .1 .70 \mathrm{~g} / \mathrm{l}$ for pure product) and it decreased slowly, indicating that the insulinaemic response would have been weak.

In humans, Mal is known to cause a lower rise in blood glucose and insulin levels (GI $=29$ and insulinaemic index $=33$ ) than a corresponding dose of glucose ${ }^{(3,18)}$. It has been demonstrated that Dex involved a glycaemic response of 25 and an insulinaemic response of $13^{(2)}$ in normal subjects.

The weak glycaemic response of both Dex and Mal cannot explain the results observed for the cereal bars because the starch content plays a major role in the glycaemic response, as explained above. As the opposite of starch, low-digestible carbohydrates induce colonic fermentations providing energetic substrates, the SCFA, over a longer period of time.

Under some severe stress conditions and increased energy demand, it has been observed that vigilance, reaction time, attention and reasoning are impaired ${ }^{(19)}$. In our stressful swimming situation, the results showed that rats of the Dex/Mal-bar group displayed better performances by gripping the rod and climbing up to the top faster than those of the standard- and Dex-bar groups. This could be explained by the better glycaemic status of rats fed with the Dex/Mal bar, allowing a high stress resistance and/or better visual information processing under the stressful conditions in water. Indeed, it has been shown that acute hypoglycaemia impairs visual information processing in healthy human subjects ${ }^{(20)}$.

Rats receiving Dex or Dex/Mal showed the best cognitive performances than those treated with $\mathrm{CoS}, 3 \mathrm{~h}$ after the administration of the cereal bars and after a physical exercise of $5 \mathrm{~min}$. This physical exercise increased carbohydrate utilisation $^{(8)}$ and permitted amplification of the difference in learning performances between the three groups of rats. Despite a trend towards significance, the total number of lever pressings was not statistically different with groups of sixteen rats, but rats fed with sugar replacers seemed to be more active than the controls and the discrimination between the two levers was improved with Dex/Mal and with the Dex bars.

It has been demonstrated that a typical breakfast of cereal rich in complex carbohydrates can help maintain mental performance (attention and memory) over the morning ${ }^{(21)}$. Similarly, it has been shown that children's performance declines throughout the morning and that this decline can be significantly reduced following the intake of a low-GI cereal as compared with a high-GI cereal on measures of accuracy of attention and memory ${ }^{(22)}$.

Other experiments need to be carried out to explain why the animals that were fed low-digestible carbohydrates improved their vigilance and learning performance in stressful conditions. One hypothesis could be that low-digestible carbohydrates induce a better management of the energy resources as postulated by Benton et al. ${ }^{(8)}$; the $\mathrm{H}_{2}$ excretion indicates the fermentation by gastrointestinal bacteria of Dex and Mal and when these fermentations occur. Van den Heuvel et al. ${ }^{(23)}$ observed that for Dex, the beginning of fermentation occurs $5 \mathrm{~h}$ after ingestion. For maltitol, Storey et al. ${ }^{(24)}$ have demonstrated that the delay was of $2.5 \mathrm{~h}$. One can assume that production of SCFA begins at 

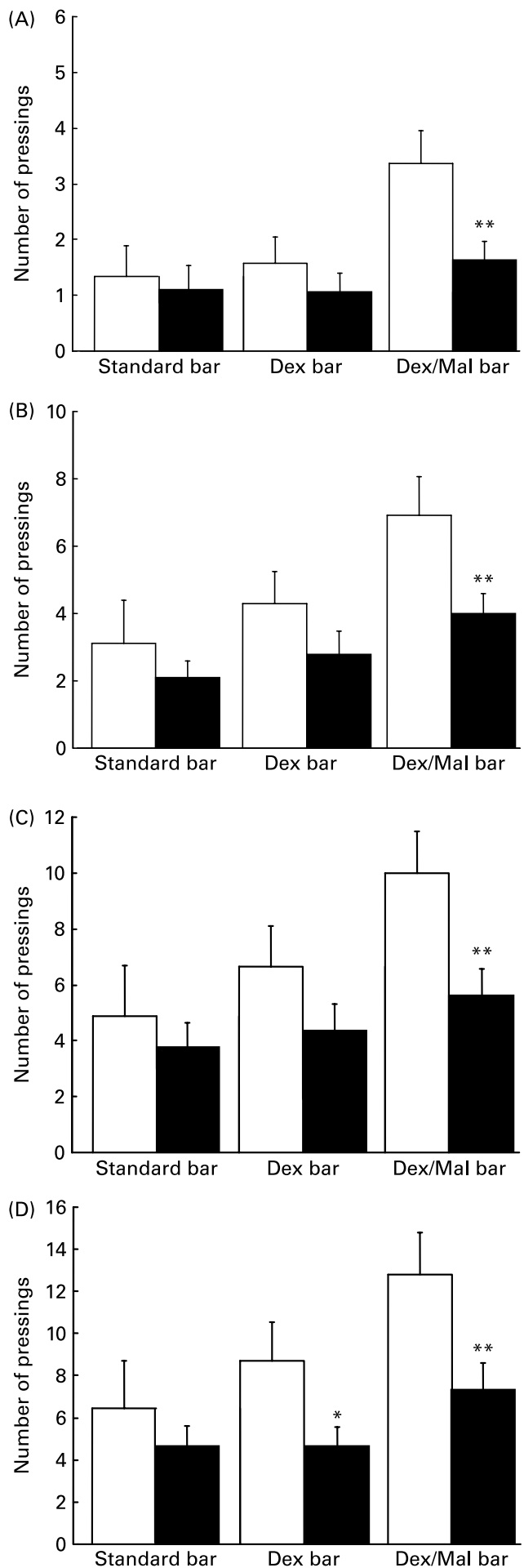

Fig. 4. Lever discrimination following ingestion of three cereal bars: standard bar containing corn syrup GLUCIDEX ${ }^{\circledR} I T$ 21; bar containing dextrin NUTRIOSE ${ }^{\circledR} 6$ (Dex bar); bar containing Dex and maltitol MALTISORB ${ }^{\circledR}$ (Dex/Mal bar). Number of active lever $(\square)$ pressings and number of inactive lever ( $\square$ ) pressings during the first $5(A), 10(B)$ and $15 \mathrm{~min}(\mathrm{C})$ and during the $20 \mathrm{~min}$ of the test (D). Values are means, with standard errors represented by vertical bars. The rat which did not eat its entire portion or did not press the two levers was discarded from the statistical analysis. Mean number of presses was significantly different from that on the active lever: ${ }^{\star} P<0.05,{ }^{\star \star} P<0.01$ (Mann-Whitney test) the same time and lasts a few hours after the start of the fermentation. Digestion in the small intestine associated with colonic fermentation explains the prolonged energy supply of certain foodstuffs or food ingredients such as soluble dietary fibres and sugar alcohols.

\section{Conclusion}

The glycaemic kinetics of a finished product is not sufficient to predict its effect on vigilance and cognitive performances. The incorporation of Dex and Mal in the bars influences the learning performances of the rats, whereas the glycaemic kinetics is similar for the three groups.

Dex and/or Mal, in combination or alone, can induce a better control of the energy resources that can be very helpful in children's nutrition and more generally in healthy nutrition.

\section{Acknowledgements}

All the authors of this paper attest that there was no potential conflict of interest that could have influenced this work, attest that no author's institution has contracts relating to this research through which it or any other organisation may stand to gain financially now or in the future, and attest that no other agreements of authors or their institutions could be seen as involving a financial interest in this work.

The financial support related to the paper was provided by ROQUETTE Frères (Lestrem, France).

All authors reviewed the contents of the submitted manuscript, approved of its contents and validated the accuracy of the data.

\section{References}

1. Vermorel M, Coudray C, Wils D, Sinaud S, Tressol JC, Montaurier C, Vernet J, Brandolini M, Bouteloup-Demange C \& Rayssiguier Y (2004) Energy value of a low-digestible carbohydrate, NUTRIOSE ${ }^{\circledR} \mathrm{FB}$, and its impact on magnesium, calcium and zinc apparent absorption and retention in healthy young men. Eur J Nutr 43, 344-352.

2. Donazzolo Y, Pelletier X, Cristiani I \& Wils D (2003) Glycaemic and insulinaemic indexes of NUTRIOSE ${ }^{\circledR} 06$ in healthy subjects. Dietary Fiber. Helsinki, 19-21 May 2003. http://www.nutriose.com/deliaRessource/ressource_id-466/ ressource_url-/deliamedia4/466_930a0f.PDF

3. Livesey G (2003) Health potential of polyols as sugar replacers, with emphasis on low glycemic properties. Nutr Res Rev 16, $163-191$.

4. Taylor RH (1979) Gastric emptying, fibre and absorption. Lancet i, 87.

5. Jenkins AL, Jenkins DJA, Zdravkovic U, Wursch P \& Vuksan V (2002) Depression of the glycaemic index by high levels of $\beta$-glucan fibre in two functional foods tested in type 2 diabetes. Eur J Clin Nutr 56, 622-628.

6. Brennan CS (2005) Dietary fibre, glycaemic response, and diabetes. Mol Nutr Food Res 49, 560-570.

7. Foster-Powell K, Holt SH \& Brand-Miller JC (2002) International table of glycemic index and glycemic load values. Am J Clin Nutr 76, 5-56.

8. Benton D, Ruffin M-P, Lassel T, Nabb S, Messaoudi M, Vinoy S, Desor D \& Lang V (2003) The delivery rate of dietary carbohydrates affects cognitive performance in both rats and humans. Psychopharmacology 166, 86-90. 
9. Burke LM, Claassen A, Hawley JA \& Noakes TD (1998) Carbohydrate intake during prolonged cycling minimizes effect of glycemic index of preexercise meal. $J$ Appl Physiol 85, 2220-2226.

10. Benton D (2001) The impact of the supply of glucose to the brain on mood and memory. Nutr Rev 59, S20-S21.

11. Anonymous (2006) Guidelines for the treatment of animals in behavioural research and teaching. Anim Behav 71, 245-254.

12. Olfert ED, Cross BM \& McWilliam AA (1993) Guide to the Care and Use of Experimental Animals, vol. 1, 2nd ed. Ottawa, ON: Canadian Council of Animal Care.

13. Olfert ED, Cross BM \& McWilliam AA (1984) Guide to the Care and Use of Experimental Animals, vol. 2. Ottawa, ON: Canadian Council of Animal Care.

14. European Union (1986) Council Directive 86/609/EEC of 24 November 1986 on the approximation of laws, regulations and administrative provisions of the Member States regarding the protection of animals used for experimental and other scientific purposes. http://eur-lex.europa.eu/LexUriServ/ LexUriServ.do?uri $=$ CELEX:31986L0609:EN:HTML

15. Messaoudi M, Tricoire A, Lalonde R, Canini F \& Minn A (1996) Effects of MPTP on lever-pressing for light extinction in rats. Eur J Pharmacol 299, 17-20.

16. Messaoudi M, Desor D, Grasmück V, Joyeux M, Langlois A \& Roman FJ (1999) Behavioral evaluation of visceral pain in rat model of colonic inflammation. Neuroreport 10, 1137-1141.

17. Macdonald I \& William CA (1988) Effects of ingesting glucose and some of its polymers on serum glucose and insulin levels in men and women. Ann Nutr Metab 32, 23-29.
18. Felber JP, Tappy L, Vouillamoz D, Randin JP \& Jequier E (1987) Comparative study of maltitol and sucrose by means of continuous indirect calorimetry. J Parent Enteral Nutr 11, $250-254$

19. Lieberman HR, Bathalon GP, Falco CM, Kramer FM, Morgan CA \& Niro P (2005) Severe decrements in cognition function and mood induced by sleep loss, heat, dehydration, and undernutrition during simulated combat. Biol Psychiatry 57, 422-429.

20. Ewing FM, Deary IJ, McCrimmon RJ, Strachan MW \& Frier BM (1998) Effect of acute hypoglycemia on visual information processing in adults with type 1 diabetes mellitus. Physiol Behav 64, 653-660.

21. Wesnes KA, Pincock C, Richardson D, Helm G \& Hails S (2003) Breakfast reduces declines in attention and memory over the morning in schoolchildren. Appetite 41, 329-331.

22. Ingwersen J, Defeyter MA, Kennedy DO, Wesnes KA \& Scholey AB (2007) A low glycaemic index breakfast cereal preferentially prevents children's cognitive performance from declining throughout the morning. Appetite 49, 240-244.

23. Van den Heuvel EGHM, Wils D, Pasman WJ, Bakker M, Saniez M-H \& Kardinaal AFM (2004) Short-term digestive tolerance of different doses of NUTRIOSE ${ }^{\circledR} \mathrm{FB}$, a food dextrin, in adult men. Eur J Clin Nutr 58, 1046-1055.

24. Storey DM, Koutsou GA, Lee A, Zumbe A, Olivier P, Le Bot Y \& Flourie B (1998) Tolerance and breath hydrogen excretion following ingestion of maltitol incorporated at two levels into milk chocolate consumed by healthy young adults with and without fasting. $J$ Nutr 128, 587-592. 